\title{
Nurses' Perception and Bedside Observation Concerning Enteral Feeding at Neonatal Intensive Care Unit
}

\author{
Noura M. Mahdy ${ }^{1}$,Marzoka A. Gadallah ${ }^{2}$, Atyat M. Hassan ${ }^{3}$ \& Safwat M. Abdel Aziz ${ }^{4}$. \\ Clinical Demonstrator in Pediatric Nursing Department, Faculty of Nursing, Assiut University, Egypt. \\ Professor of Pediatric and Premature Nursing, Faculty of Nursing, Assiut University, Egypt \\ Lecturer of Pediatric and Premature nursing, Faculty of Nursing, Assiut University, Egypt. \\ Lecturer of Pediatrics, Faculty of Medicine, Assiut University, Egypt.
}

\begin{abstract}
Background: Enteral feeding (EF) is the preferred method of feeding for high-risk neonates. So, major attention should be directed to nurses' perception and bedside observation concerning EF. Aim: This study aimed to determine nurses' perception and bedside observation concerning EF at NICU. Design: Descriptive research design was utilized. Setting: This study was carried out at NICU in Assiut University Children Hospital. Subjects: A convenience sampling of 60 nurses who had clinical experience at least three months in NICU was included. Tools: Two tools were used to collect necessary data which included; personal characteristics questionnaire for nurses (tool 1) and enteral feeding questionnaire (tool 2). Results: $48.33 \%$ of the studied nurses had high level of perception and more than half $(58.33 \%)$ of them had high level of practice concerning enteral feeding, $100 \%$ of the studied nurses who aged 35 years and more and the majority of them who had 10 years and more of experiences had high level of perception and practice ( 85.2 and $96 \%$ respectively). Conclusion: About half of the studied nurses had high level of perception and more than half of them had high level of practice concerning enteral feeding. More experienced, attendance training programs and aged nurses had high level of enteral feeding perception and practice. Recommendations: Provision of continuing educational programs on regular basis is suggested in order to refresh and updated nurses' perception and practice.
\end{abstract}

Keywords: Bedside Observation, Enteral Feeding, Nurses' Perception \& Neonatal Intensive Care Unit.

\section{Introduction}

Nutritional support is a regular part of neonates. It should be started as soon as possible after admission and should be maintained as long as the infant doesn't feed adequately. The neonate's brain is uniquely sensitive to nutrition, other organs and tissues are also at critical developmental stages in early infancy; because it is an optimizing nutrient intake during the hospitalization in the Neonatal Intensive Care Unit (NICU). Also, it has the potential to benefit long-term neurodevelopment and health outcome (Burdall et al., 2017).

Current parenteral and enteral nutrition recommendations for preterm infants are designed to provide nutrients, which approximate the rate of growth and composition of weight gain to maintain normal concentrations of blood and tissue nutrients .Enteral nutrition is more physiologic, less expensive and safer than parenteral nutrition due to reduced exposure to a central venous catheter (Koletzko et al., 2014) Earlier initiation of enteral nutrition is associated with decreased gastrointestinal inflammation and it has immunologic advantages (Viswanathan et al., 2017).

Accurate tube placement in the body of the stomach is very important to ensure safe and effective enteral feeding. In fact, malposition of feeding tubes may be associated to gastric bleeding, aspiration or gastrooesophageal reflux problems, mechanical complications including obstruction, displacement or dislodgement of the tube and infection-related complications occur infrequently as a result of handling, storage and administration of formulas (Thoene et al., 2018).

Nursing care is continuously changing in all aspects including feeding. Therefore, it is crucial for pediatric nurses to be updated with the current evidences and major attention must be focused on nurses' perception and bedside observation concerning enteral feeding tube because pediatric nurses have the major responsibility for providing infants with their essential nutrients. Nurses' perception in applying enteral feeding is very important factor to prevent any complications, as well as adequacy and convenient nursing intervention should be observed and are needed for an effective enteral feeding (Wilson et al., 2015).

Nurses' perception is a complex question and the pediatric nurse must have enough information, theoretical from lecture, training programs, articles and books or practical experience from work in hospitals. Also, infants' outcomes are affected by nursing care quality (Khalil et al., 2017).

The role of pediatric nurse in delivering the tube feeding usually includes selection appropriate of size for feeding tube, insertion of the tube, maintenance of the tube placement by checking the position of the tube prior to each feed or each medication and 4 
hourly if infant receiving continuous feeds, checking the tube patency, assessment methods of securing tube or method of feeding, participation in assessment of the infant's response to tube feeding and prevention and detection of complications associated with enteral feeding tube. Adequate feeding and taking necessary nutrition for infants in NICU depend on the perception and bedside observation of pediatric nurses, which requires applying essential guidelines of enteral feeding to deliver the best care (AL Kalaldeh et al., 2015).

\section{Significance of the study}

Nurses are very important link in nutritional support because they are responsible for administering nutritional formula. Enteral feeding is the most frequently used method for delivery of a complete feeding to the infants and it is associated with reduced period of hospital stay, reduced mortality, lower costs and fewer complications for infants (Seres, 2010).

For effective administration of enteral feeding, pediatric nurses who are responsible for administering this care need to have a sufficient knowledge and clear responsibilities. A study done by Darawad et al., (2015) in Jordan found that nurses had inadequate knowledge of nutritional assessment concerning nutritional care of their infants. So that the researcher wanted to conduct this study to determine nurses' perception and bedside observation concerning enteral feeding.

\section{Aim of the study}

This study aimed to determine nurses' perception and bedside observation concerning enteral feeding at Neonatal Intensive Care Unit.

\section{Research Questions}

1. What are the nurses' perception of responsibility, knowledge, documentation and enteral feeding interventions concerning enteral feeding at NICU?

2. What are the nurses' practices concerning enteral feeding at NICU?

\section{Subjects \& Method \\ Operational definitions}

Perception: Refers to expertise and skill acquired through education or experience, and the theoretical or practical understanding of enteral nutrition issues.

Bedside observation: This describes the nurses' methods of providing tube feeding.

Research design: A descriptive research design was utilized in this study.

Setting: This study was conducted at the NICU in Assiut University Children Hospital. This unit services more than one provinces from EL minia to
Red Sea province, it contains 50 incubators and the mean of total admission every month was 127 neonates. NICU contains 13 rooms, examination room, seven rooms to care for neonates with critical conditions, bed room for stable conditions who were just on phototherapy, feeding preparation, clinical pharmacy, incubator sterilization and breast feeding rooms. Also, NICU contains ten mechanical ventilators for critically ill neonates.

Subjects: The subjects of this study consisted of all nurses (60 nurses) who were working at the NICU in Assiut University Children Hospital and had clinical experience for at least three months.

Tools of data collection: Two tools were used to collect the required data for this study:

Tool (1): Personal characteristics questionnaire for nurses: It was developed by the researcher to collect the required information such as: age, sex, educational level, years of experience at the NICU and attending training programs about feeding.

Tool (2): Enteral feeding questionnaire: It was adopted from Persenius et al., (2006) to assess nurses' perception and bedside observation concerning enteral feeding and it included two parts:

Part (1): Nurses' perception questionnaire: It was used to assess the nurses' opinions about enteral feeding. It was consisted of 29 questions with 49 items in responsibility, knowledge, documentation and enteral feeding interventions concerning enteral feeding. Using 5-point Likert scale ranging from (1) "very small extent" to (5) "very great extent". The mean score of each item was calculated out of five, with a score less than 3 considered as low, from 3 to less than 4 considered as moderate, and from 4 to 5 considered as high. the total score of nurses' perception is out of 130 by summation the score of responsibility, knowledge, documentation, and enteral feeding interventions, with a score less than 78 considered as low, 78-103 considered as moderate, and 104-130 considered as high.

Part (2): Bedside observation checklist: It was consisted of 17 items concerning nursing interventions. Each item was scored as Yes or No. The total score of nurses' bedside observation is out of 16 , with a score less than 10 considered as low, 10-12 considered as moderate, and 13-16 considered as high. Scoring system: Scoring system for nurses' perception and bedside observation is summed and classified to: Low: less than 88 score. Moderate: from 88 to 116 score. High: more than 116 score.

Validity of tool two was tested by measuring its contents validity index by five expert jury in both Pediatric Nursing and Pediatrics field and its result was 0.953 .

Reliability was measured by Cronbach's alpha coefficient for enteral feeding questionnaire and its 
result was $r=0.864$ assessed by Persenius et al., (2006).

\section{Pilot study}

A pilot study was carried out on 6 nurses (10\%) of total nurses to test the clarity and applicability of the study tools and to estimate time needed to fulfill each sheet and the final form was developed. No modifications were done and they were included in the study sample.

\section{Method of data collection}

An official permission was obtained from the chairmen of NICU in Assiut University Children Hospital to collect the necessary data for this study. Written nurses' consent for their participation in the study was obtained after explaining the aim of the study.

\section{Ethical considerations}

Research proposal was approved from Ethical Committee in the Faculty of Nursing, Assiut University. Nurses were assured that the data of this research was used only for the purpose of research. Confidentiality and anonymity was assured. Nurses had the right to refuse to participate and or withdraw from the study without any rational any time.

\section{Field of the work}

This study was carried out through a period of four months from the beginning of December 2018 to the end of March 2019. The actual work started by meeting the nurses throughout the morning and after- noon shifts. First the researcher gave them a complete background about the study aim and explained that this information is used for the purpose of scientific research only. The time needed for every nurse was 45 minutes (30 minutes for filling the sheet and 15 minutes for bedside observation checklist) and the researcher was taken two nurses every day.

In the first part of tool two the researcher determined the perception of the studied nurses concerning enteral feeding by asking them about their responsibility, knowledge and their support from documentation, through assessment of infant' nutritional status, how were they determined goals, planning and implementation, prevention of complication and evaluation of the infant' condition. And the second part of tool two was filled by observing every nurse during enteral feeding care.

Statistical analysis of data

Data entry and data analysis were done by using SPSS program version 22. The content of each tool was analyzed, categorized and then coded. Data were presented using descriptive statistics in the form of frequencies, percentage, mean and standard deviation. Chi- square test was used to compare qualitative data. Spearman correlation was used to measure correlation between the studied nurses' level of perception and practice concerning enteral feeding. $\mathrm{P}$ value considered statistically significant when $\mathrm{p}<0.05$.

\section{Results}

Table (1): Percentage distribution of the studied nurses according to their personal data $(n=60)$.

\begin{tabular}{|c|c|c|}
\hline Personal data & $\mathrm{No}=60$ & $\%$ \\
\hline \multicolumn{3}{|l|}{ Age/ years: } \\
\hline Less than 25 & 19 & 31.67 \\
\hline From 25 to less than 35 & 32 & 53.33 \\
\hline 35 and more & 9 & 15 \\
\hline Mean \pm SD & \multicolumn{2}{|c|}{$28.37 \pm 6.55$} \\
\hline \multicolumn{3}{|l|}{ Sex: } \\
\hline Female & 58 & 96.7 \\
\hline Male & 2 & 3.3 \\
\hline \multicolumn{3}{|l|}{ Current job: } \\
\hline Nurse & 52 & 86.7 \\
\hline Nursing specialists & 8 & 13.3 \\
\hline \multicolumn{3}{|l|}{ Educational level: } \\
\hline Secondary school of nursing & 24 & 40.0 \\
\hline Technical institute of nursing & 28 & 46.7 \\
\hline Bachelor's degree in nursing & 8 & 13.3 \\
\hline \multicolumn{3}{|l|}{ Years of experience/years: } \\
\hline Less than 5 years & 27 & 45.0 \\
\hline From 5 to less than 10 & 6 & 10.0 \\
\hline 10 and more & 27 & 45.0 \\
\hline Mean \pm SD & \multicolumn{2}{|c|}{$8.65 \pm 7.34$} \\
\hline \multicolumn{3}{|l|}{ Attending training programs: } \\
\hline Yes & 41 & 68.3 \\
\hline No & 19 & 31.7 \\
\hline
\end{tabular}


Table (2): Perception of the studied nurses regarding responsibility, knowledge and documentation concerning enteral feeding $(n=60)$.

\begin{tabular}{|c|c|c|c|c|c|c|c|c|c|c|}
\hline \multirow[t]{2}{*}{ Questions } & \multicolumn{2}{|c|}{$\begin{array}{c}\text { Very small } \\
\text { extent }\end{array}$} & \multicolumn{2}{|c|}{ Small extent } & \multicolumn{2}{|c|}{$\begin{array}{c}\text { Neither small } \\
\text { nor great extent }\end{array}$} & \multicolumn{2}{|c|}{ Great extent } & \multicolumn{2}{|c|}{$\begin{array}{c}\text { Very great } \\
\text { extent }\end{array}$} \\
\hline & No & $\%$ & No & $\%$ & No & $\%$ & No & $\%$ & No & $\%$ \\
\hline \multicolumn{11}{|l|}{ Responsibility } \\
\hline $\begin{array}{ll}\text { Assessment } & \text { of } \\
\text { nutritional status }\end{array}$ & 2 & 3.3 & 13 & 21.7 & 13 & 21.7 & 23 & 38.3 & 9 & 15.0 \\
\hline $\begin{array}{l}\text { Goal of nutritional } \\
\text { assessment }\end{array}$ & 3 & 5.0 & 12 & 20.0 & 13 & 21.7 & 27 & 45.0 & 5 & 8.3 \\
\hline $\begin{array}{lr}\text { Planning } & \text { and } \\
\text { implementation } & \text { of } \\
\text { interventions } & \end{array}$ & 3 & 5.0 & 11 & 18.3 & 17 & 28.3 & 24 & 40.0 & 5 & 8.3 \\
\hline $\begin{array}{ll}\begin{array}{l}\text { Prevention } \\
\text { complications }\end{array} & \text { of } \\
\end{array}$ & 0 & 0 & 9 & 15.0 & 17 & 28.3 & 17 & 28.3 & 17 & 28.3 \\
\hline $\begin{array}{ll}\text { Evaluation } & \text { of } \\
\text { nutritional status }\end{array}$ & 1 & 1.7 & 8 & 13.3 & 17 & 28.3 & 15 & 25.0 & 19 & 31.7 \\
\hline \multicolumn{11}{|l|}{ Knowledge } \\
\hline $\begin{array}{ll}\text { Assessment } & \text { of } \\
\text { nutritional status }\end{array}$ & 0 & 0 & 11 & 18.3 & 22 & 36.7 & 15 & 25.0 & 12 & 20.0 \\
\hline $\begin{array}{l}\text { Goal of nutritional } \\
\text { assessment }\end{array}$ & 0 & 0 & 10 & 16.7 & 22 & 36.7 & 17 & 28.3 & 11 & 18.3 \\
\hline $\begin{array}{lr}\text { Planning } & \text { and } \\
\text { implementation } & \text { of } \\
\text { interventions } & \end{array}$ & 0 & 0 & 13 & 21.7 & 17 & 28.3 & 21 & 35.0 & 9 & 15.0 \\
\hline $\begin{array}{ll}\begin{array}{l}\text { Prevention } \\
\text { complications }\end{array} & \text { of } \\
\end{array}$ & 0 & 0 & 6 & 10.0 & 19 & 31.7 & 24 & 40.0 & 11 & 18.3 \\
\hline $\begin{array}{ll}\text { Evaluation } & \text { of } \\
\text { nutritional status }\end{array}$ & 0 & 0 & 6 & 10.0 & 18 & 30.0 & 21 & 35.0 & 15 & 25.0 \\
\hline \multicolumn{11}{|l|}{ Documentation } \\
\hline $\begin{array}{ll}\begin{array}{l}\text { Assessment } \\
\text { nutritional status }\end{array} & \text { of } \\
\end{array}$ & 0 & 0 & 2 & 3.3 & 21 & 35.0 & 32 & 53.3 & 5 & 8.3 \\
\hline $\begin{array}{l}\text { Goal of nutritional } \\
\text { assessment }\end{array}$ & 0 & 0 & 3 & 5.0 & 22 & 36.7 & 30 & 50.0 & 5 & 8.3 \\
\hline $\begin{array}{lr}\text { Planning } & \text { and } \\
\text { implementation } & \text { of } \\
\text { interventions } & \end{array}$ & 0 & 0 & 5 & 8.3 & 23 & 38.3 & 26 & 43.3 & 6 & 10.0 \\
\hline $\begin{array}{l}\text { Prevention } \\
\text { complications }\end{array}$ & 0 & 0 & 2 & 3.3 & 27 & 45.0 & 21 & 35.0 & 10 & 16.7 \\
\hline $\begin{array}{ll}\text { Evaluation } & \text { of } \\
\text { nutritional status }\end{array}$ & 0 & 0 & 7 & 11.7 & 24 & 40.0 & 15 & 25.0 & 14 & 23.3 \\
\hline
\end{tabular}

Table (3): Percentage distribution of the studied nurses' perception regarding enteral feeding intervention $(\mathbf{n}=60)$.

\begin{tabular}{|c|c|c|c|c|c|c|c|c|c|c|}
\hline \multirow[t]{2}{*}{ Questions } & \multicolumn{2}{|c|}{ Never } & \multicolumn{2}{|c|}{ Almost never } & \multicolumn{2}{|c|}{$\begin{array}{c}\text { Neither } \\
\text { never nor } \\
\text { always }\end{array}$} & \multicolumn{2}{|c|}{$\begin{array}{l}\text { Almost } \\
\text { always }\end{array}$} & \multicolumn{2}{|c|}{ Always } \\
\hline & No & $\%$ & No & $\%$ & No & $\%$ & No & $\%$ & No & $\%$ \\
\hline \multicolumn{11}{|l|}{ Enteral feeding intervention } \\
\hline $\begin{array}{l}\text { 1-Flush tube before } \\
\text { administration of nutrition or } \\
\text { medication? }\end{array}$ & 16 & 26.7 & 5 & 8.3 & 11 & 18.3 & 22 & 36.7 & 6 & 10.0 \\
\hline $\begin{array}{l}\text { 2-Flush tube after administration } \\
\text { of nutrition or medication? }\end{array}$ & 0 & 0 & 0 & 0 & 0 & 0 & 21 & 35.0 & 39 & 65.0 \\
\hline 3-Daily inspection of nostrils? & 1 & 1.7 & 17 & 28.3 & 10 & 16.7 & 17 & 28.3 & 15 & 25.0 \\
\hline 4-Medications that are & 2 & 3.3 & 10 & 16.7 & 21 & 35.0 & 18 & 30.0 & 9 & 15.0 \\
\hline
\end{tabular}




\begin{tabular}{|c|c|c|c|c|c|c|c|c|c|c|}
\hline \multirow[t]{2}{*}{ Questions } & \multicolumn{2}{|c|}{ Never } & \multicolumn{2}{|c|}{ Almost never } & \multicolumn{2}{|c|}{$\begin{array}{c}\text { Neither } \\
\text { never nor } \\
\text { always }\end{array}$} & \multicolumn{2}{|c|}{$\begin{array}{l}\text { Almost } \\
\text { always }\end{array}$} & \multicolumn{2}{|c|}{ Always } \\
\hline & No & $\%$ & No & $\%$ & No & $\%$ & No & $\%$ & No & $\%$ \\
\hline $\begin{array}{l}\text { administered through feeding } \\
\text { tube not to be crushed? }\end{array}$ & & & & & & & & & & \\
\hline $\begin{array}{l}\text { 5-Clean nutritional equipment } \\
\text { after each use? }\end{array}$ & 0 & 0 & 0 & 0 & 11 & 18.4 & 18 & 30.0 & 31 & 51.7 \\
\hline 6-Continuous feed? & 1 & 1.7 & 18 & 30.0 & 16 & 26.7 & 18 & 30.0 & 7 & 11.7 \\
\hline 7-Bolus feed? & 0 & 0 & 3 & 5.0 & 27 & 45.0 & 24 & 40.0 & 6 & 10.0 \\
\hline 8-Check gastric residual? & 3 & 5.0 & 15 & 25.0 & 10 & 16.7 & 16 & 26.7 & 16 & 26.7 \\
\hline $\begin{array}{l}\text { 9- Does feeding schedule allow } \\
\text { for a night rest? }\end{array}$ & 60 & 100 & 0 & 0 & 0 & 0 & 0 & 0 & 0 & 0 \\
\hline 10- Use of feeding pump? & 2 & 3.3 & 18 & 30.0 & 16 & 26.7 & 18 & 30.0 & 6 & 10.0 \\
\hline $\begin{array}{l}\text { 11- Confirm tube placement } \\
\text { before every delivery? }\end{array}$ & 0 & 0 & 1 & 1.7 & 6 & 10.0 & 23 & 38.3 & 30 & 50.0 \\
\hline
\end{tabular}

Table (4): Percentage distribution of the studied nurses' practice concerning enteral feeding intervention $(n=60)$.

\begin{tabular}{|c|c|c|c|c|c|c|}
\hline \multirow{2}{*}{ Questions } & \multicolumn{3}{|c|}{ Yes } & \multicolumn{3}{|c|}{ No } \\
\hline & \multicolumn{2}{|c|}{ No. } & $\%$ & No. & \multicolumn{2}{|c|}{$\%$} \\
\hline \multicolumn{7}{|l|}{ Enteral feeding intervention } \\
\hline Is the feeding tube securely fastened with tape? & & & 100 & 0 & \multicolumn{2}{|c|}{0} \\
\hline Is the feeding tube taped without risk of damaging the eye? & & & 91.7 & 5 & \multicolumn{2}{|c|}{8.3} \\
\hline Is the feeding tube taped on undamaged skin? & & 4 & 90.0 & 6 & \multicolumn{2}{|c|}{10.0} \\
\hline Is the feeding tube fixed without straining the nose? & & & 73.3 & 16 & \multicolumn{2}{|c|}{26.7} \\
\hline Is the feeding tube fixed on the cheek? & & 6 & 43.3 & 34 & \multicolumn{2}{|c|}{56.7} \\
\hline Is a feeding pump used? & & 4 & 73.3 & 16 & \multicolumn{2}{|c|}{26.7} \\
\hline Is administration set for enteral feeding used? & & 8 & 80.0 & 12 & \multicolumn{2}{|c|}{20.0} \\
\hline Is the feeding pump labeled only for tube feeding? & & 3 & 71.7 & 17 & \multicolumn{2}{|c|}{28.3} \\
\hline Is the feeding pump labeled? & & 3 & 71.7 & 17 & \multicolumn{2}{|c|}{28.3} \\
\hline Is the tube labeled for feeding tube? & & 6 & 76.7 & 14 & \multicolumn{2}{|c|}{23.3} \\
\hline Is the syringe labeled only for feeding tube? & & & 53.3 & 28 & \multicolumn{2}{|c|}{46.7} \\
\hline Is the syringe replaced daily according to date label? & & 0 & 100 & 0 & \multicolumn{2}{|c|}{0} \\
\hline Is the syringe kept dry? & & 8 & 80.0 & 12 & \multicolumn{2}{|c|}{20.0} \\
\hline $\begin{array}{l}\text { Infant position while receiving enteral nutrition? } \\
\text { a) Supine (head elevated) }\end{array}$ & & 0 & 100 & 0 & \multicolumn{2}{|c|}{0} \\
\hline b) Right lateral & & & 0 & 60 & \multicolumn{2}{|c|}{100} \\
\hline c) Left lateral & & 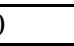 & 0 & 60 & \multicolumn{2}{|c|}{100} \\
\hline Backrest elevation? 45 degree & & & 100 & 0 & \multicolumn{2}{|c|}{0} \\
\hline $\begin{array}{l}\text { What kind of feeding tube is used? } \\
\text { Small bore }\end{array}$ & & 4 & 90.0 & 6 & \multicolumn{2}{|c|}{10.0} \\
\hline Wide bore jejunostomy & & 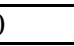 & 0 & 60 & \multicolumn{2}{|c|}{100} \\
\hline Gastrostomy & & & 10.0 & 54 & \multicolumn{2}{|c|}{90.0} \\
\hline \multirow[t]{3}{*}{ Can gurgling sounds be heard during exhalation? } & \multicolumn{2}{|c|}{ Yes } & \multicolumn{2}{|c|}{ No } & \multicolumn{2}{|c|}{$\begin{array}{c}\text { Not } \\
\text { applicable* }\end{array}$} \\
\hline & No. & $\%$ & No. & $\%$ & No. & $\%$ \\
\hline & 53 & 88.3 & 1 & 1.7 & 6 & 10.0 \\
\hline
\end{tabular}

* Not applicable because of surgical operations in abdomen. 


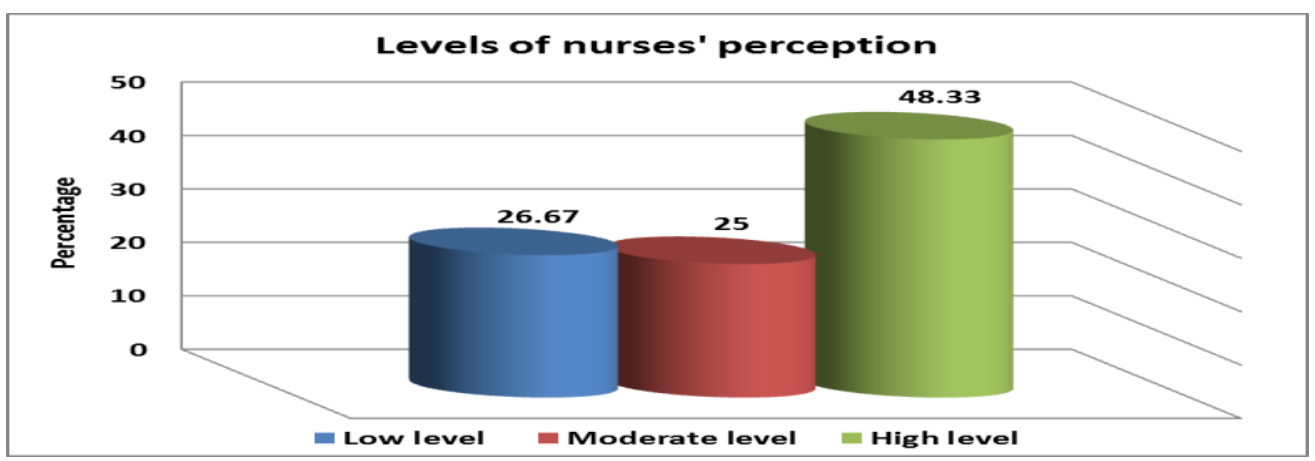

Figure (1): Total level of the studied nurses' perception concerning enteral feeding.

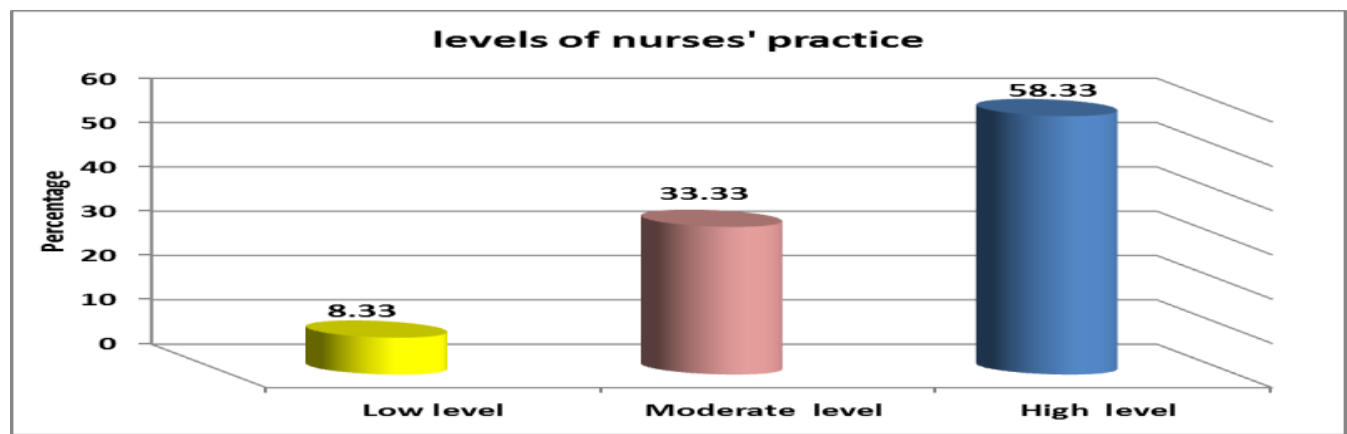

Figure (2): Total level of the studied nurses' practice concerning enteral feeding.

Table (5): The relation between the studied nurses' perception concerning enteral feeding and their personal data $(n=60)$.

\begin{tabular}{|c|c|c|c|c|c|c|c|c|c|}
\hline \multirow{3}{*}{ Personal data } & \multirow{3}{*}{ No. } & \multicolumn{8}{|c|}{ Levels of nurses' perception } \\
\hline & & \multicolumn{2}{|c|}{$\begin{array}{c}\text { Low } \\
\text { (less than 78) }\end{array}$} & \multicolumn{2}{|c|}{$\begin{array}{c}\text { Moderate } \\
(78-103)\end{array}$} & \multicolumn{2}{|c|}{$\begin{array}{c}\text { High } \\
(104-130)\end{array}$} & \multirow[t]{2}{*}{$\mathbf{X}^{2}$} & \multirow{2}{*}{ p. value } \\
\hline & & No. & $\%$ & No. & $\%$ & No. & $\%$ & & \\
\hline \multicolumn{8}{|l|}{ Age/ years: } & \multirow{4}{*}{33.1} & \multirow{4}{*}{$0.000 * *$} \\
\hline Less than 25 & 19 & 12 & 63.2 & 7 & 36.8 & 0 & 0 & & \\
\hline From 25 to less than 35 & 32 & 4 & 12.5 & 8 & 25.0 & 20 & 62.5 & & \\
\hline 35 and more & 9 & 0 & 0 & 0 & 0 & 9 & 100 & & \\
\hline \multicolumn{8}{|l|}{ Sex: } & \multirow{3}{*}{5.69} & \multirow{3}{*}{$0.05 *$} \\
\hline Female & 58 & 14 & 24.0 & 15 & 26.0 & 29 & 50.0 & & \\
\hline Male & 2 & 2 & 100 & 0 & 0 & 0 & 0 & & \\
\hline \multicolumn{8}{|l|}{ Current job: } & \multirow{3}{*}{3.82} & \multirow{3}{*}{0.15} \\
\hline Nurse & 52 & 16 & 31.0 & 13 & 25.0 & 23 & 44.0 & & \\
\hline Nursing specialists & 8 & 0 & 0 & 2 & 25.0 & 6 & 75.0 & & \\
\hline \multicolumn{10}{|l|}{ Educational level: } \\
\hline Secondary school of nursing & 24 & 0 & 0 & 3 & 12.5 & 21 & 87.5 & \multirow{3}{*}{39.70} & \multirow{3}{*}{$0.000 * *$} \\
\hline Technical institute of nursing & 28 & 16 & 57.0 & 10 & 36.0 & 2 & 7.0 & & \\
\hline Bachelor's degree in nursing & 8 & 0 & 0 & 2 & 25.0 & 6 & 75.0 & & \\
\hline \multicolumn{8}{|l|}{ Years of experience: } & \multirow{4}{*}{33.21} & \\
\hline Less than 5 years & 27 & 12 & 44.4 & 9 & 33.3 & 6 & 22.2 & & \multirow{3}{*}{$0.000 * *$} \\
\hline From 5 to less than 10 & 6 & 4 & 66.7 & 2 & 33.3 & 0 & 0 & & \\
\hline 10 and more & 27 & 0 & 0 & 4 & 14.8 & 23 & 85.2 & & \\
\hline \multicolumn{10}{|l|}{ Attending training programs: } \\
\hline Yes & 41 & 10 & 24.4 & 10 & 24.4 & 21 & 51.2 & \multirow{2}{*}{7.38} & \multirow{2}{*}{$0.025^{*}$} \\
\hline No & 19 & 8 & 42.1 & 3 & 15.8 & 8 & 42.1 & & \\
\hline
\end{tabular}


Table (6): The relation between the studied nurses' level of practice concerning enteral feeding and their personal data $(n=60)$.

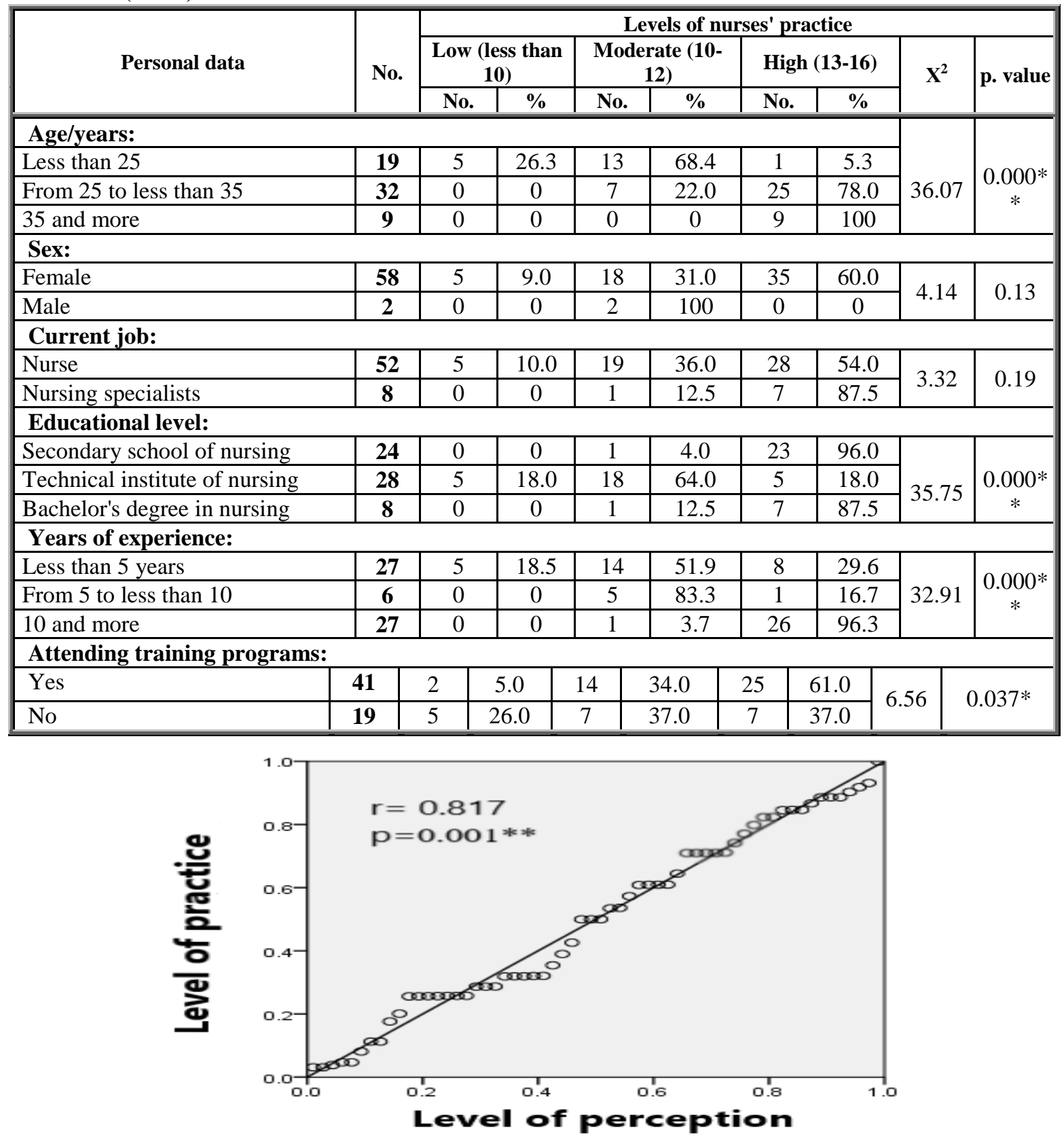

Figure (3): The correlation between the studied nurses' level of perception and practice concerning enteral feeding.

Table (1): Shows percentage distribution of the studied nurses according to their personal data. It was revealed that more than half $(53.33 \%)$ of the studied nurses were in the age group from 25 to less than 35 years. Also, the vast majority $(96.7 \%)$ of them were females. Likewise, $86.7 \%$ of the studied nurses their current job were nurse. As regards the educational level, near half $(46.7 \%)$ of them were graduated from technical institute of nursing. Regarding years of experience, it was noticed that $45 \%$ of the studied nurses had experience less than 5 years and from 10 years and more. Furthermore, more than two-thirds $(68.3 \%)$ of them attended training programs concerning feeding.

Table (2): Presents perception of the studied nurses regarding responsibility, knowledge and 
documentation concerning enteral feeding. It was clarified that about two-fifths of the studied nurses were responsible to a "great extent" about determining goal and planning \& implementation of interventions $(45 \% \& 40 \%$ respectively). Also, twofifths of them had satisfying knowledge to a "great extent" as regards prevention of complications. Likewise, more than half $(53.3 \%)$ of the studied nurses had support from documentation to a "great extent" according to assessment of nutritional status and half $(50 \%)$ of them had support from documentation to a "great extent" regarding determining goal.

Table (3): Illustrates percentage distribution of the studied nurses' perception regarding enteral feeding intervention. It was found that $(65 \%)$ of the studied nurses "always" flushed tube after administration of nutrition or medication. Furthermore, more than half $(51.7 \%)$ of them "always" cleaned nutritional equipment after each use. In addition; half (50\%) of them "always" confirmed tube placement before every delivery. Likewise, all of the studied nurses' $(100 \%)$ reported that feeding schedule "never" allowed for a night rest.

Table (4): Presents the studied nurses' practice concerning enteral feeding intervention. It was observed that all of the studied nurses (100\%) securely fastened the feeding tube with tape, replaced the syringe daily according to date label, placed the infants in a supine position (with head elevated) during receiving enteral nutrition and with backrest elevation 45 degree. Furthermore, the majority of them taped the feeding tube without risk of damaging the eye and skin $(91.7 \%$ \& $90 \%$ respectively).

Figure (1): Shows the total level of the studied nurses' perception concerning enteral feeding. Findings revealed that $48.33 \%$ of the studied nurses had high level of perception concerning enteral feeding. While one-quarter $(25 \%)$ of them had moderate level of perception concerning enteral feeding.

Figure (2): Demonstrates the total level of the studied nurses' practice concerning enteral feeding. Findings revealed that more than half $(58.33 \%)$ of the studied nurses had high level of practice concerning enteral feeding. While only $(8.33 \%)$ of them had low level of practice concerning enteral feeding.

Table (5): Illustrates the relation between the studied nurses' perception concerning enteral feeding and their personal data. There was highly statistical significant relation between the studied nurses' level of perception concerning enteral feeding and their age, educational level, and years of experience with $\mathrm{p}$. value (0.000). The studied nurses whose age from 35 and more, their years of experience $10 \mathrm{yrs}$ and more and attended training programs had high level of perception concerning enteral feeding.
Table (6): Represents the relation between the studied nurses' level of practice concerning enteral feeding and their personal data. There was highly statistical significant relation between the studied nurses' level of practice concerning enteral feeding and their age, educational level, and years of experience with $\mathrm{p}$. value (0.000). The studied nurses whose age from 35 and more, their years of experience $10 \mathrm{yrs}$ and more and attended training programs had high level of practice concerning enteral feeding.

Figure (3): Shows the correlation between the studied nurses' level of perception and practice concerning enteral feeding. It was indicated that, there was statistically significant positive correlation between the studied nurses' level of perception and practice with p- value (0.001).

\section{Discussion}

Enteral feeding is the preferred method of infant feeding because it promotes gastrointestinal maturity, has immunologic advantages and meets nutritional requirements better than Parenteral Nutrition (PN). The use of a standardized enteral feeding guideline improves growth outcomes, reduces the incidence of NEC, reduces mortality and hospital-acquired infections (Stefanescu et al., 2018).

According to the studied nurses' responsibility, knowledge and documentation concerning enteral feeding, it was found that the studied nurses had responsibility and knowledge to a "great" \& "very great extent" regarding of prevention of complications of enteral feeding and evaluation than assessment of nutritional status and establishing goals. Also, the studied nurses had support from documentation to a "great"\& "very great extent" regarding assessment of nutritional status, establishing goal, planning and implementation of interventions, prevention of complications and evaluation concerning enteral feeding. These results were in the same line with Hayter et al., (2015) who found that in terms of nursing processes, nurses showed greater level of knowledge and responsibility for prevention of complications and evaluation more than assessment and identifying goals.

These results may be explained that following all septic techniques during enteral feeding helped the studied nurses to prevent complications and evaluate infants' nutritional status. Using health information system in documentation was very accurate and helped them to document all infant's data quickly and accurately.

The results of present study showed that concerning enteral feeding intervention, all of the studied nurses "almost always" and "always" flushed the feeding tube after administration. Also, one-quarter of them "always" daily inspect the nostrils and more than half 
of the studied nurses "always" cleaned the nutritional equipment after each use. These results were in agreement with Hayter et al., (2015) who indicated that nurses normally flushed feeding tube more often after administration than before. Also, they were daily inspecting the nostrils, and they cleaned syringe after each use.

These results explained that, it was an ordinary act to flush feeding tube and all nutritional equipment after administration to keep them clean, ready for next use and to prevent complications of feeding. The studied nurses also, daily inspect the nostrils as a routine care to observe redness, swollen, injury and strain from tape.

The results of current study referred that near onethird of the studied nurses "almost always" used continuous feed and feeding pump for enteral feeding. Also, half of them "always" confirmed tube placement before every delivery and enteral feeding schedule didn't allow for a night rest. These were the same results reached by Persenius et al., (2006) \& Hayter et al., (2015) who reported that feeding pump was used for enteral feeding and the feeding schedule didn't allow for a night rest. These results were attributed to that syringe pump was available in NICU and was used if needed. Also, the placement of feeding tube was confirmed before every delivery to make sure that the feeding tube in its place in the stomach. In NICU, enteral feeding was given for infants every two hours so that it didn't allow for a night rest.

The present study indicated that near half of the studied nurses had high level of perception concerning enteral feeding. These findings were supported by AL-Hawaly et al., (2016) who found that the studied nurses had a satisfactory level of perception regarding enteral feeding administration. While these findings were disagreement with Morphet et al., (2016) who indicated that perception deficit was prevalent among the studied nurses' in relation to enteral nutrition.

From the researcher's point of view, these results were caused by the availability of consulting colleagues were the first source of knowledge and training programs that helped them to refresh their knowledge and had high level of perception concerning enteral feeding.

As regard of the studied nurses practice concerning enteral feeding intervention, the results of current study showed that feeding tube was securely fastened with tape without risk of damaging the eye, skin and without straining the nose, administration set was used for enteral feeding and the feeding pump was labeled only for tube feeding. These results were agreed with a study conducted by Persenius et al., (2006) who noted that enteral feeding tube always securely fastened without risk of damaging the eye or being taped over-damaged skin, it didn't cause strain to the nose, an administration set for enteral feeding always used and all feeding pumps were used during practice labeled only for enteral use.

These results attributed that the studied nurses were very clever and had high experience in securely fastened the feeding tube with tape, without risk of damaging the eye, skin and without straining the nose. Also, infection control team in hospital had very important role in making all nurses aware with labeled of feeding tube and feeding pump.

The current study revealed that all of the studied nurses replaced the syringe daily according to date label and kept it dry, placed the infants in a supine position (with head elevated) during receiving enteral nutrition and with backrest elevation 45 degree. These results were supported by Persenius et al., (2006) who reported that the syringe was replaced within $24 \mathrm{hrs}$ according to the labeling of date, time for replacement, and kept it dry. Also, the infants' backrest elevation during receiving enteral nutrition was more than 30 degree.

These results can be explained in the fact that, from NICU policy that the syringe should be replaced daily according to date label and infection control team who had rounds in the unit to make sure that all policies of infection control were applicable.

The results of current study indicated that more than half of the studied nurses had high level of practice and one third of them had moderate level of practice concerning enteral feeding. These results were inconsistent with Marzangu et al., (2017) who referred that the mean score of the studied nurse's practice about performance of enteral feeding was smaller than the standard score. Also, these results disagreed with AL-Hawaly et al., (2016) who found that more than half of the studied nurses had an unsatisfactory level of practice regarding enteral feeding administering. These results may be because as the nurse grew older, she was more responsible and had more practical work in direct patient care than younger ones. In addition to, attending training program was associated with significant improvement of nurses' practice.

The results of present study revealed that there was highly statistically significant relation between the total level of the studied nurses' perception concerning enteral feeding and their age. The majority of nurses was female and had technical institute of nursing as the most frequent educational level. These findings were in accordance with ALHawaly et al., (2016) who found that most of the study subjects were female and had nursing institute as the most frequent educational attainment. While these findings disagree with Khalil (2017) \& Abo 
EL-Ata, et al., (2016) who noted that about twothirds of the studied nurses had secondary diploma of nursing.

These results may be because the more number of nursing schools which involved females and nurses were graduated from technical institute of nursing were more professional and more experienced than secondary school of nursing.

The current study denoted that there was highly statistically significant relation between the total level of the studied nurses' practice concerning enteral feeding and their years of experience. Also, the majority of them who had 10 years of experience had high level of practice concerning enteral feeding. This result was disagree with AL-Hawaly et al., (2016) who indicated that two-fifths of the studied nurses had previous experience less than one year and about one-quarter of them had from 5 to less than 10 years of experience.

These results might be due to the more years of experience the more level of practice concerning enteral feeding. Also, from the studied nurses' experience in the unit, they became very clever, skillful and had good experience regarding enteral feeding.

Finally, the results of present study showed that there was a significant positive correlation between the studied nurses' perception and level of practice concerning enteral feeding. This result was in agreement with Ahmed \& Mondal (2014) who found that there was statistical significant positive correlation between the studied nurses' perception and practice regarding enteral feeding. While this result was in disagreement with AL-Hawaly et al., (2016) who indicated that there was no statistical significant correlation between total nursing perception and practice about enteral feeding.

From the researcher's point of view, this results denoted that when the studied nurses' had high level of perception concerning enteral feeding from doctors, consulting colleagues, training programs, nursing schools or from any other source of knowledge, this helped them to be skillful and had high level of practice concerning enteral feeding.

\section{Conclusion}

Based on the results of the present study, it could be concluded that

About half of the studied nurses had high level of perception and more than half of them had high level of practice concerning enteral feeding. The perception and practice of the studied nurses whose ages were 35 and more, their work experience was more than 10 years and who attended training programs were high level concerning enteral feeding. There was a significant positive correlation between the studied nurses' perception and level of practice concerning enteral feeding.

\section{Recommendations}

Based on the results of the present study it could be recommended that

1. Nutritional team should be found in every unit and at the hospital as a consultation source for nurses in all information concerning feeding.

2. Provision of continuing educational programs on regular basis is suggested in order to refresh and updated nurses' perception and practice, as well as reinforce proper procedures related to enteral feeding.

3. Continuous evaluation of effectiveness of these courses on nurses through supervision and evaluation of their clinical skills especially enteral feeding care.

\section{References}

1. Abo EL-Ata A., Bedier N., \& Shehab M., (2016): Effect of educational program on nurses' practice related to nasogastric tube feeding. International Journal of Caring Sciences; Vol 9(2):432- 437.

2. Ahmed N., \& Mondal D., (2014): Assessment of perception and practice of staff nurses regarding enteral feeding. SMU Medical Journal; Vol 1(2): pp 294-302.

3. AL Kalaldeh M., Watson R., \& Hayter M., (2015): Jordanian nurses' knowledge and responsibility for enteral nutrition in the critically ill. Nursing in critical care; Vol 5(2):29-41.

4. AL-Hawaly N., Ibrahim H., \& Qalawa A., (2016): Assessment of nurses' perception and performance regarding enteral feeding. Med. J. Cairo Univ; Vol 48(2): 99- 105.

5. Burdall C., Howarth A., \& CH Lee A., (2017): Pediatric enteral tube feeding. Pediatric and child health Journal; Vol 27(8): 371-376.

6. Darawad M., Al-Hussami M., Boshaiqah A., Ayman M., \& Mansour H., (2015): Investigating critical care nurses' perception regarding enteral nutrition. Nurse Education Today; Vol 8(35), 414-419.

7. Hayter M., Al Kalaldeh M., \& Watson R., (2015): Jordanian nurses' perception and responsibility for enteral nutrition in the critically ill. British Association of Critical Care Nurses; Vol 20 (5): 229- 239.

8. Khalil, N., (2017): Impact of implementing an educational program regarding care of nasogastric tube feeding on nurses' knowledge and performance. Journal of Nursing and Health Science; Vol 6(1), 101-109. 
9. Koletzko B., Poindexter B., \& Uauy R., (2014): Nutritional Care of Preterm Infants. Scientific Basis and Practical Considerations. Third Edition, Elsevier Inc, chapter 6; pp 210230.

10. Marzangu H., Esteki T., Naderiravesh N., Babapour K., Pourhoseingholi A., \& Esmaeili R., (2017): Nurses' practice about performance of enteral feeding in intensive care unit. International Journal of Advanced Biotechnology and Research (IJBR); Vol 7(5): pp1585-1594.

11. Morphet S., Juli E., Clarke N., Angelique B., \& Bloomer M., (2016): Intensive care nurses' perception of enteral nutrition: a descriptive questionnaire. Intensive and critical care nursing; Vol 37(9):68- 74.

12. Persenius W., Larsson W., \& Hall-Lord L., (2006): Enteral nutrition in intensive care nurses' perceptions and bedside observations. Intensive and Critical Care Nursing; Vol 22(7):82- 94.

13. Seres D., (2010): Overview of nutritional support in critically ill patients. SM Medical Journal; Vol 1(2): 294-302.

14. Stefanescu B., Gillam-Krakauer M., Markham M., \& Kosinski J., (2018): Very low birth weight infant care: adherence to a new nutrition protocol improves growth outcomes and reduces infectious risk. Early Hum; Vol 94(15): 25-30.

15. Thoene M., Lyden E., \& Anderson-Berry A., (2018): Improving nutrition outcomes for infants $<1500$ Grams with a progressive, evidenced-based enteral feeding protocol. Nutr Clin Pract; Vol 33(6): 47-55.

16. Viswanathan S., Merheb R., Wen X., (2017): Standardized slow enteral feeding protocol reduces necrotizing enterocolitis in micropremies. J Neonatal perinatal med; Vol 10(1): 71-80.

17. Wilson J. Singh B., Dutta S., (2015): Guidelines for enteral feeding. Journal of Nursing Education and Practice; Vol (6), 150155. 